\title{
Mitteilungen der Schweizerischen Menopausengesellschaft / SMG
}

J. Gynäkol. Endokrinol. 2017 · 20:162

https://doi.org/10.1007/s41975-017-0014-0

(c) Springer-Verlag GmbH Austria 2017

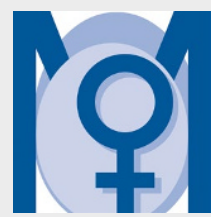

Präsidentin

Prof. Dr. med. Petra Stute (V.i. S. d. P.)

Administration SMG

Weißdornweg 17

D-35041 Marburg/Lahn

Tel.: +49 (0) 62093444

E-Mail: administration@meno-pause.ch
Liebe Kolleginnen und Kollegen!

Zum nächsten Women's Health Kongress lade ich Sie herzlich nach Zürich ein.

Wir hoffen, dass wir mit den folgenden Sessions Ihr Interesse getroffen haben, und freuen uns auf rege Diskussionen gemeinsam mit Ihnen:

\section{Komplementärmedizin bei Östrogenmangelfolgen nach gynäkologischen Tumoren \\ - Vasomotorische Symptome \\ - Therapiemöglichkeiten bei Genitalatrophie und Störun- gen der sexuellen Funktion \\ - Management der Knochen- gesundheit nach Mamma- karzinom \\ - Kardioprotektion bei Östro- genmangel}

\section{Frauengesundheit: \\ Du bist, was Du isst}

- Orale Gesundheit der Frau $40+$

- Schilddrüsenfunktion in den Wechseljahren

- Omega-3-Fettsäuren: Einsatzmöglichkeiten bei Stimmungsschwankungen oder Depression in der Menopause

Ebenfalls wird während des Kongresses der SMG-Wissenschafts- preis verliehen werden. Hierbei wird besonderer Wert auf die wissenschaftliche Bearbeitung der Fragestellungen, die sich fachübergreifend aus zahlreichen Bereichen wie Diabetologie, Ernährungswissenschaft, Innere Medizin, Kardiologie, Onkologie, Ophthalmologie, Osteologie etc. ergeben, und auf die Förderung des interdisziplinären Dialogs gelegt.

Wir würden uns sehr freuen, Sie zu begrüßen.

Mit kollegialen Grüssen,

Ihre Petra Stute

Präsidentin Schweizerische Menopausengesellschaft

\section{Wissenschaftspreis}
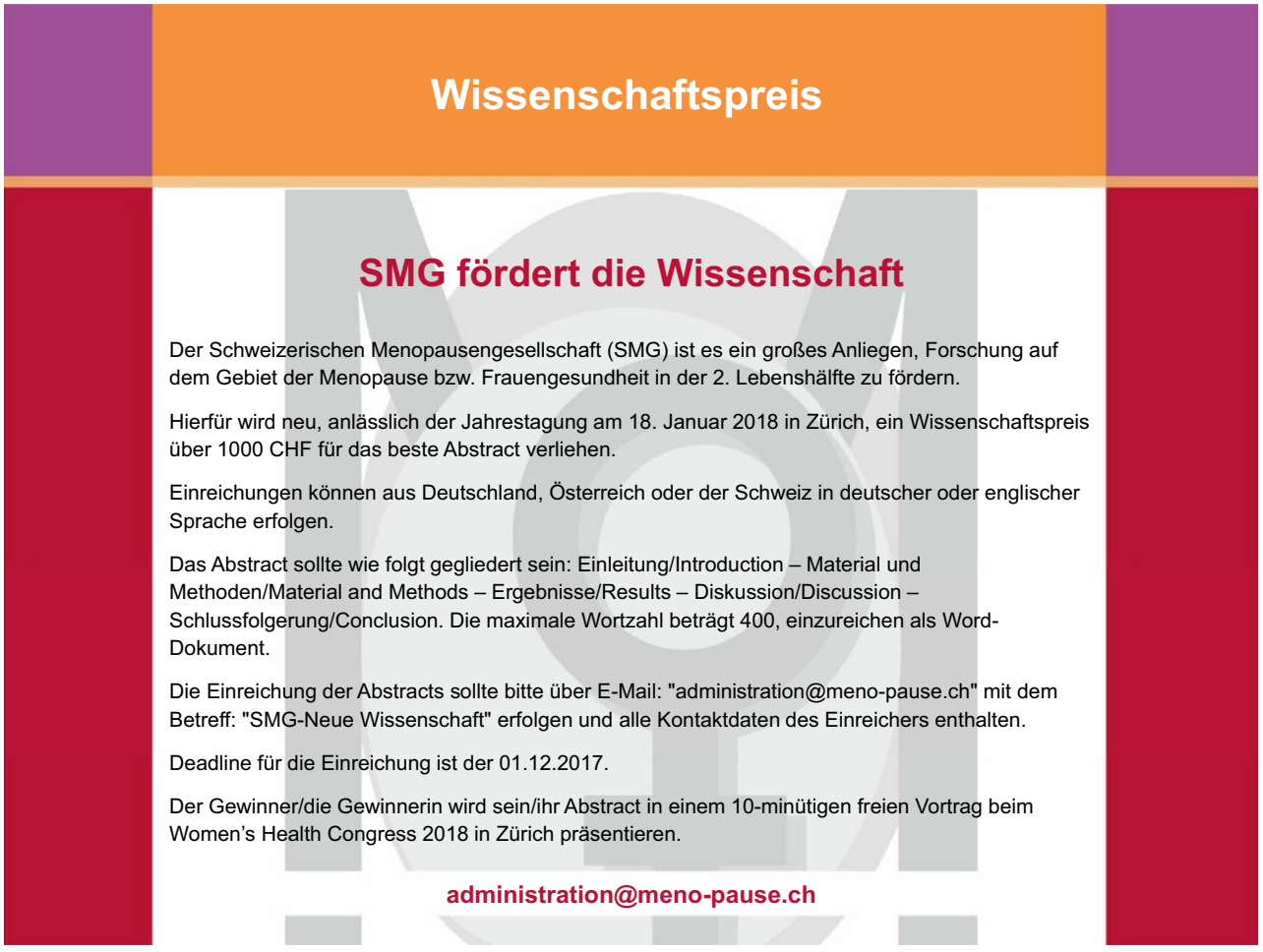

A Informationen, u. a. auch zu einer Mitgliedschaft in der SMG erhalten Sie von: Administration Schweizerische Menopausengesellschaft - SMG -, Anne Becker, Weißdornweg 17, 35041 Marburg/Lahn, Deutschland, Tel.: +49 (0)6420 93444, E-Mail: administration@meno-pause.ch 